\title{
Evolution of joint probability methods in coastal engineering practice in the UK
}

\author{
Dominic P. Hames BEng, MSc, PhD, CEng, MCIWEM \\ Principal Engineer, HR Wallingford Ltd., Oxfordshire, UK \\ (corresponding author: d.hames@hrwallingford.com) \\ (Orcid:0000-0001-9506-280X)

\section{Ben P. Gouldby BSc} \\ Chief Technical Director, HR Wallingford Ltd., Oxfordshire, UK \\ (Orcid:0000-0003-0415-5897)
}

Peter J. Hawkes BEng, PhD

Principal Engineer (retired), HR Wallingford Ltd., Oxfordshire, UK (Orcid:0000-0002-4616-1155)

This paper outlines the evolution of joint probability methods in the design and assessment of sea defence structures in the UK, together with the key drivers for these different methods. It highlights why and how the joint exceedance curve techniques were developed initially from the late 1980s and early 1990s, as well as the reasons for the later development of the Join-Sea software system in the mid-1990s, as well as more recently, the implementation of more robust multivariate statistical approaches. The differences between these techniques are outlined, as well as potential errors accounting for how these different techniques are applied to assess different sea defence response functions.

\section{Notation \\ $C_{\mathrm{F}} \quad$ correlation factor \\ $H_{\mathrm{s}} \quad$ significant wave height \\ $p_{\mathrm{E}} \quad$ probability of response \\ $\eta \quad$ sea level}

\section{Introduction}

It has long been recognised that overtopping and damage at coastal locations are usually associated with periods of high sea levels combined with significant wave activity, and their joint occurrence is relevant and needs to be considered when assessing overtopping rates and damage (Hames, 2006). Large, locally generated waves tend to occur during periods of low pressure and high wind speeds, usually resulting in a surge, an increase in sea levels above astronomic levels. As a result, the largest waves are more likely to occur at the same time as the highest sea levels and surge levels, resulting in a positive correlation between onshore waves and sea levels. This joint occurrence of wave heights and sea levels is therefore crucial in the assessment of the performance of sea defence structures and the methods adopted can significantly influence the design and the estimated actual flood risks.

Despite this long recognition of the importance of the joint occurrence of wave heights and sea levels in the assessment of sea defences in the UK, statistically rigorous methods for assessing this joint occurrence in coastal engineering did not exist until the mid- to late 1980s. Before this, the assessment of sea defence structures was typically considered based on the notion of design wave heights and sea levels, and assumptions on wave steepness (a function of wave period) and breaking. This was defined by the coastal engineer based on their experience and judgement; an approach commonly referred to as 'engineering judgement'. However, with the increasing availability of wave height and sea-level data from about the late 1980s onwards, the ability to consider joint extremes and new approaches were developed. These typically considered the joint exceedance of wave height and sea-level combinations, with a similar assumption on wave steepness as for the engineering judgement approach, which resulted in the well-known wave height and sea-level joint exceedance curves (see e.g. Simm et al., 1996). These approaches are also commonly referred to as joint probability curves. With the ability to be used with limited data sets for the simplest techniques, and similarly to previous engineering judgement approaches, these techniques quickly became embedded in many engineering studies, forming the basis of risk and probability analysis for many engineering designs over the 1990 s.

However, with more data available with the passage of time, as well as a consequent increase in computing power in the early to mid-1990s, there was a clear recognition during this period that more work was required for the development of joint probability methods in flood and sea defence. A series of studies was therefore commissioned by the Ministry of Agriculture, Fisheries and Food (MAFF) from the mid-1990s on joint probability, leading to new methods being developed or revised (MAFF was later merged into the Department for Environment, Food and Rural Affairs (Defra)). This research resulted in the well-known Join-Sea (JS) statistical approach being developed (Hawkes et al., 2002; HR Wallingford, 2000a, 2000b), which enabled for the first time a risk-based approach, whereby the probability of exceeding a response variable (RV) of interest such as the wave overtopping rate could be determined directly (see e.g. Sayers 
et al., 2002). This was in contrast to the aforementioned joint exceedance curves that work in terms of the probability of wave heights and sea levels, which in general do not relate to exceedance probabilities of RVs. This risk-based approach is termed the RV approach in this paper. Using the multivariate extreme approach of Heffernan and Tawn (2004), further work into joint probability methods following the severe UK winter storms of 2013/2014 (Met Office, 2014) has subsequently led to further improvements in the RV approach (Gouldby et al., 2017; HR Wallingford, 2015). The response of a structure can now be assessed based on a significantly increased number of variables, as opposed to a limit of three within JS. The RV approaches, although developed as a replacement for the joint exceedance curve approaches, also facilitate the production of more robust joint exceedance curves should these still be required, such as in the optimisation of designs in physical model tests. Since their development, RV approaches have been used increasingly across the coastal engineering community, including in all Environment Agency National Flood Risk Assessments since their inception in 2004 (HR Wallingford, 2004), although their take-up is still limited. However, joint exceedance curve techniques continue to be used extensively by the coastal engineering community in situations that could be inappropriate, resulting in analyses that are not robust.

\section{Historical review of joint probability methods in UK practice}

\subsection{Introduction}

Methods for predicting joint (multivariate) extremes naturally followed the development of predictions of single (univariate) extremes, a subject which was developed from the 1940s, with environmental factors (sea levels, river flow, wave heights etc.) being the most common application (Hames, 2006). It was not until the 1950s that the topic of univariate extremes was expanded to multivariate extremes, and not until the mid-1980s that publications appeared dealing with applications of this theory. Similar to univariate extremes (i.e. early applications concentrated on environmental factors) with applications in insurance, financial and later Internet traffic management from the late 1980s onwards (see the historical review of Kotz and Nadarajah, 1999). However, these methods of multivariate extreme value analyses were based on a high level of dependency between all variables. This is not the case for many environmental factors, such as sea levels and waves, which have a low level of dependency (Hames, 2006). Methods were therefore proposed by Ledford and Tawn $(1996,1997)$ which dealt with analysing multivariate extremes with a low level of dependency.

\subsection{Evolution of methods}

Prior to the $1980 \mathrm{~s}$, the application of joint probability methods in flood and sea defence was fairly rare (Hames, 2006).
Although extreme offshore wave heights and sea levels were two of the main early applications of extreme value theory, data were not readily available in a form suitable to consider their joint occurrence. Few long-term records of offshore wave heights existed, and if they did, they were often difficult and expensive to obtain. If they were available, wave transformation modelling to the nearshore zone was also expensive and time consuming, and not practical for more than a few cases. There were limited digital tide gauge records available until the early 1990 s, and as a consequence, estimates of these extremes were usually based on annual maxima sea-level records, which were not suitable for a joint probability assessment. Many early joint probability studies were therefore carried out on the basis of a standard wave height and a standard sea level, generally referred to as a design condition (Hames, 2006). A conservative assessment would represent design conditions by the univariate extreme of the wave height and sea level separately assuming full dependence, as indicated in Figure 1. However, most engineers recognised that this was an overly conservative approach for two variables that were not fully dependent. This is particularly the case for regions of high tidal range such as the Severn Estuary and the East Irish Sea where extreme sea levels are dominated by the tidal component. In these regions, it was generally recognised that damage and overtopping to shoreline structures were predominantly driven by large surges coincident with large spring tides, when waves may not necessarily be high or extreme.

As a consequence, there was a recognition that design conditions would probably be represented by a combination of wave heights and sea levels in a short time period where at least one of these variables would have a univariate extreme noticeably smaller than the design extreme (typically neither variable is particularly extreme, even under well-correlated conditions). This led to the 'engineering judgement' approach outlined in concept in Figure 1, where wave height and sea-level combinations were tested, with the one that gave the worst damage and/or overtopping set as the design condition. In some cases, a misunderstanding of the concept of joint probability led some to assume that the design condition was represented by the product of the annual exceedance probabilities, or return periods (RPs) of the univariate extremes of the form

1. $\mathrm{RP}=\mathrm{RP}_{\eta} \times \mathrm{RP}_{H_{\mathrm{s}}}$

where RP is the return period of the design condition in years, and $\mathrm{RP}_{\eta}$ and $\mathrm{RP}_{H_{\mathrm{s}}}$ are the RPs of the sea level $(\eta)$ and wave height $\left(H_{\mathrm{s}}\right)$ in years, respectively, based on records within a short time period (e.g. a few hours or a tidal cycle). This would be correct if this was for uncorrelated wave heights and sea levels occurring independently at any point in the same year, but not for coincident wave heights and sea levels occurring over a shorter time period (e.g. a tidal cycle), which is required 


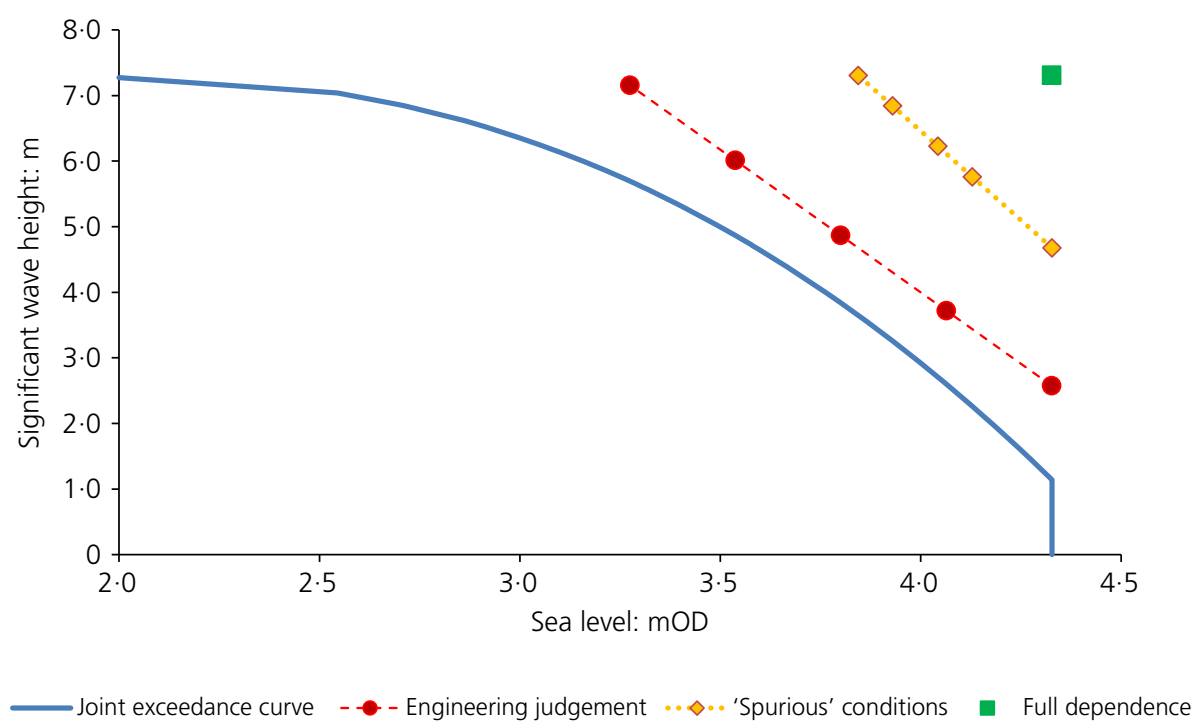

Figure 1. Typical methodologies applied in the late 1980s/early 1990s prior to the introduction of the joint exceedance curve approaches

for assessing flood risk and damage. This presented what is outlined in Figure 1 as 'spurious' conditions. Where applied, this approach invariably led to a significant overestimate of design wave and sea-level conditions for a given joint exceedance RP as it inherently indicated a significant level of correlation between wave heights and sea levels that in reality did not exist.

The importance of the joint probability of waves and high sea levels within the UK was brought into sharp focus as a result of the Towyn floods in North Wales in late February 1990. A combination of large onshore wave heights and the highest sea levels ever recorded along this stretch of the North Welsh coastline at this time resulted in significant coastal flooding and damage over a period of several days. As a result of this flood event, Hydraulics Research Limited (now HR Wallingford Ltd) was commissioned by the Welsh Office to establish the joint probability relationship between extreme wave heights and high sea levels along the North Wales coastline (Hydraulics Research Limited (HRL, 1990)). The magnitude of this event as well as the wide dissemination of this report led to significant awareness of this approach across the coastal engineering community. Although not the first time it had been used, it outlined an approach based on the limited data available and gave a more rigorous estimation of potential design conditions than previous methods, such as engineering judgement. Potential design conditions were defined as a 'curve' of combinations of wave heights and sea levels (usually at high water), with wave period typically defined based on an assumption on wave steepness. This approach is demonstrated for one of its earliest applications for Shoreham in Sussex in
Figure 2. In this figure, the joint exceedance curves for low RPs were drawn in manually directly from the data. Higher RP events were then sketched in manually, maintaining the shape of the joint exceedance curves for lower RP events, with the marginal data used to fix the extremes. As with the engineering judgement approach, each combination was tested, with design conditions defined as the pair that gave the worst result for the RV of interest.

The increased awareness and ease of use of this approach, as well as its more sound scientific principles compared with previous methods, meant that it quickly became embedded in many engineering studies, forming the basis of many engineering designs and risk and probability analyses over the 1990s. The similarities to the engineering judgement approach may also have explained the rapid acceptance and adoption of this approach at this time.

As a result of the events at Towyn, and more work into joint probability, a consistent theme in the first generation of shoreline management plans (SMPs) issued in the mid- to late 1990s, it was clear that more research in this area was required MAFF. Therefore commissioned a series of research projects on joint probability from the mid-1990s. This resulted in new methods being developed or revised, the most advanced of which were based on the work of Ledford and Tawn (1996, 1997). The main output was the JS statistical approach, which often based on direction, facilitated the fitting of extreme value distributions to each variable within a multivariate data set (known as marginal extreme value distributions) and their dependence function using what are now 


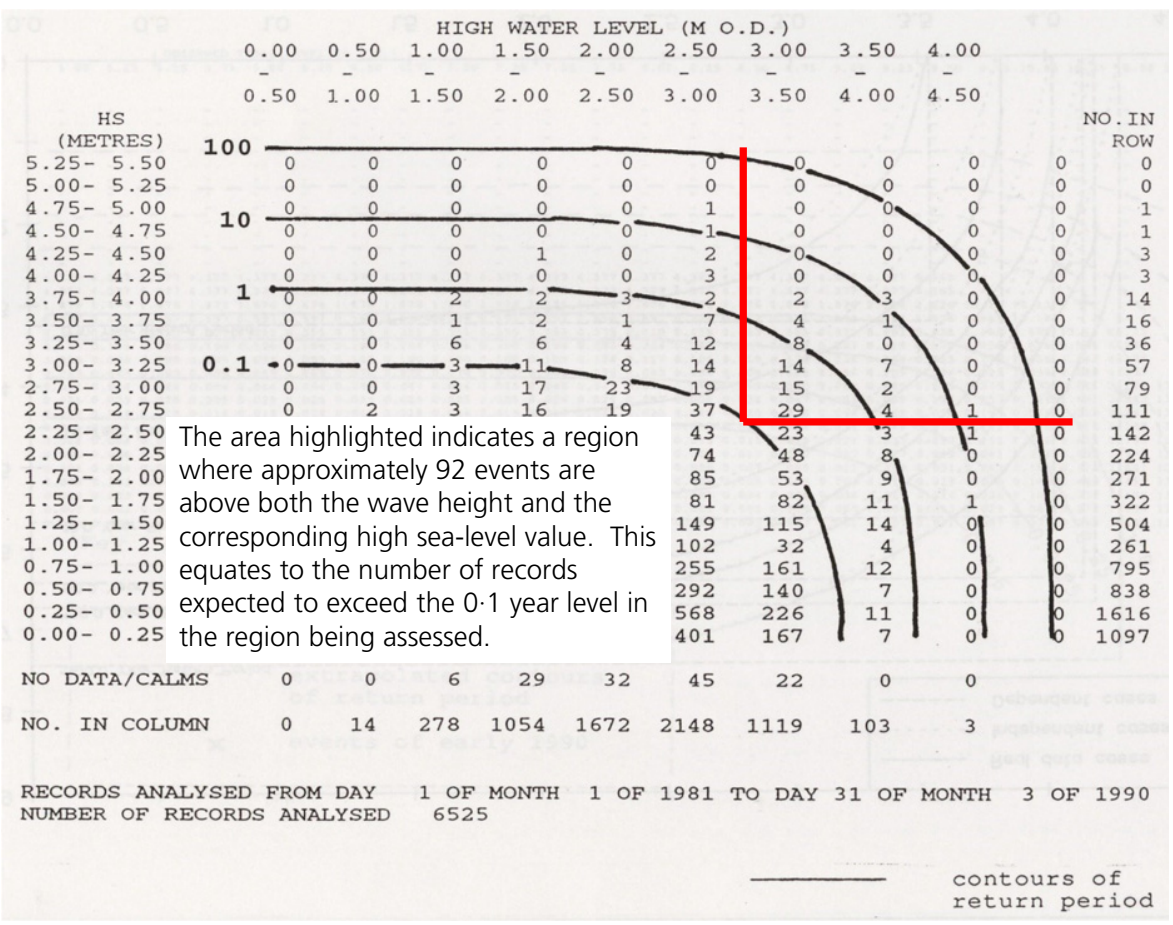

Figure 2. Example of an early use of the COMJEC approach as applied for Shoreham in Sussex based on $9 \cdot 2$ years of coincident records (after HR Wallingford, 1992)

standard copula approaches (see e.g. De Michele et al., 2007). Once fitted, the approach facilitated the generation of many years of synthetic events in the form of pairs of wave heights and sea levels, with surge considered instead of sea levels in some cases where it could be reliably estimated. A third parameter, wave period, was represented by a linear regression model fitted to the wave steepness above a chosen wave height threshold. This approach enabled for the first time a robust estimate of extreme RVs such as wave forces or overtopping rate to be determined directly - that is, the RV approach. This approach therefore removed the inconsistency of estimating the RV of interest by the joint exceedance of wave heights and water levels or similar approaches previously applied up to this point (Hawkes et al., 2002). This RV JS approach was subsequently used in a number of major studies, including the National Flood Risk Assessment from its inception in 2004 until 2009, although less so across the coastal engineering community at large.

However, with the winter period of 2013/2014 resulting in unprecedented levels of disruption caused by flooding to large parts of the country, this re-emphasised the threat to the UK posed by coastal flooding. In response to this, the Environment Agency recognised that improved information relating to the analysis of coastal flood risk was required. This resulted in a new joint probability approach based on the multivariate extreme value statistical approach of Heffernan and Tawn (2004), and drawing on a scoping study carried out by Hames et al. (2013). This approach, although similar in concept to JS, enabled coastal flood risk to be considered based on the assessment of a wider range of variables (as opposed to three within JS). This allowed extreme and typical values of one variable to be modelled conditional on extreme values of a second variable (Ewans and Jonathan, 2014), resulting in variables such as wind speed being incorporated in the analysis. This approach was subsequently applied to the revised National Flood Risk Assessment (Gouldby et al., 2017; HR Wallingford, 2015), where seven variables were considered (wave height, period, direction and directional spreading, wind speed and direction and sea level). This approach also considered events based on peaks of sea level, wave height and wind speed, whereas traditionally only peaks in sea level have been considered.

\section{Common joint probability methods in current use in the UK}

As joint probability methods have evolved since their first use in any volume in the early 1990s, three approaches are now considered to be in common use around the UK coastlines. These are outlined in Table 1, with additional details on whether the 
Table 1. Statistical approaches commonly used to define the joint probability relationship

\begin{tabular}{|c|c|c|c|}
\hline \multirow[b]{2}{*}{ Approach } & \multicolumn{2}{|c|}{ Statistical approaches commonly used } & \multirow[b]{2}{*}{ Comments } \\
\hline & JS & HT & \\
\hline COMJEC & Yes & No & $\begin{array}{l}\text { Heffernan and Tawn (2004) (HT) method could equally be applied here. However, it is } \\
\text { believed that few studies have used this approach to produce joint probability curves. }\end{array}$ \\
\hline InJoPA & $\mathrm{n} / \mathrm{a}$ & $\mathrm{n} / \mathrm{a}$ & $\begin{array}{l}\text { Distribution of univariate extremes is a relatively simple task to define, so no } \\
\text { specialised statistical methodology is necessary. }\end{array}$ \\
\hline RV & Yes & Yes & \\
\hline
\end{tabular}

JS or the Heffernan and Tawn (HT) approach are believed to be typically used to define the joint probability relationship.

Further details of these different joint probability approaches are given below. Other approaches that may have been used in the past, or may currently be applied elsewhere are given for example in Serinaldi (2014).

\subsection{Composite marginal joint exceedance curve approach}

The composite marginal joint exceedance curve (CoMJEC) is a joint exceedance curve approach that was developed around the late 1980s; as noted in Section 2.2, this approach started to be extensively used within the coastal engineering community in the aftermath of the Towyn floods of 1990 (see e.g. Hames, 2006). Although it is commonly referred to as a joint exceedance curve (or joint probability curve), in this paper it is referred to as the CoMJEC to distinguish it from other different joint exceedance curve approaches.

The basis of the CoMJEC approach is that the probability of the response, $p_{\mathrm{E}}$, can be represented in terms of combinations of wave heights and sea levels that have the same exceedance probability over the same unit of time. This gives a continuous curve of combinations with $p_{\mathrm{E}}$ defined as

2. $\quad p_{\mathrm{E}}=p\left(H_{\mathrm{s}} \geq y \cap \eta \geq x\right)$

Using this approach, a value of the RV is determined based on each wave height and sea-level combination that lie on a specific contour, with the largest value of the RV from these combinations corresponding to the response probability of interest. Wave period, a crucial parameter in the assessment of many RVs, is typically represented as a function of wave steepness, which is usually assumed to be a constant for large wave heights. An example of the CoMJEC approach is given in Figure 3, showing the calculation of the peak overtopping rate for a 1 year event from a 10 year data set, where each point on the curve is typically exceeded by ten wave height-sea-level pairs. An assessment of the peak overtopping rate for each of these pairs gives the peak overtopping rate curve shown, with the 1 year RP peak overtopping rate, $0.0018 \mathrm{~m}^{3} / \mathrm{s} / \mathrm{m}$, defined as the highest point on this curve.

Initially developed at a time when few suitable wave and sealevel data were available, this approach initially evolved over two overlapping stages, which were

manual analysis of joint probability density

- extrapolation of the joint probability density above several wave height and high sea-level thresholds.

The first stage was when the RP of an event was determined directly from a scatter diagram of coincident pairs of wave height and sea-level data in the same way as indicated in Figure 2. With more (time series) data available, it later became possible to utilise the second stage, where based on several years of simultaneous wave height and sea-level data, extremes could be determined by extrapolating wave heights and sea levels for successively rarer wave heights and sea levels to produce contours of equal exceedance. This was typically done based on the Weibull distribution for wave heights, and the Pareto or Gumbel distribution for sea levels. Although more rigorous than the first stage, the lack of large data sets meant that the corresponding reduction in data for the larger wave height and sea-level combinations meant that extrapolations in these regions were unreliable, with the user possibly having to revert to the first stage in these regions.

However, since the advent of JS in the mid-1990s, these stages have mainly become obsolete. These curves are now believed to be mainly determined using the JS approach, and in more recent years, by the HT approach.

\subsection{Intuitive joint probability assessment or correlation factor approach}

The intuitive joint probability assessment (InJoPA) approach was originally proposed by Hawkes and Hague (1994) and was specifically designed for cases where only information on marginal extremes was available. It probably became widely used as a result of its publication in the first edition 


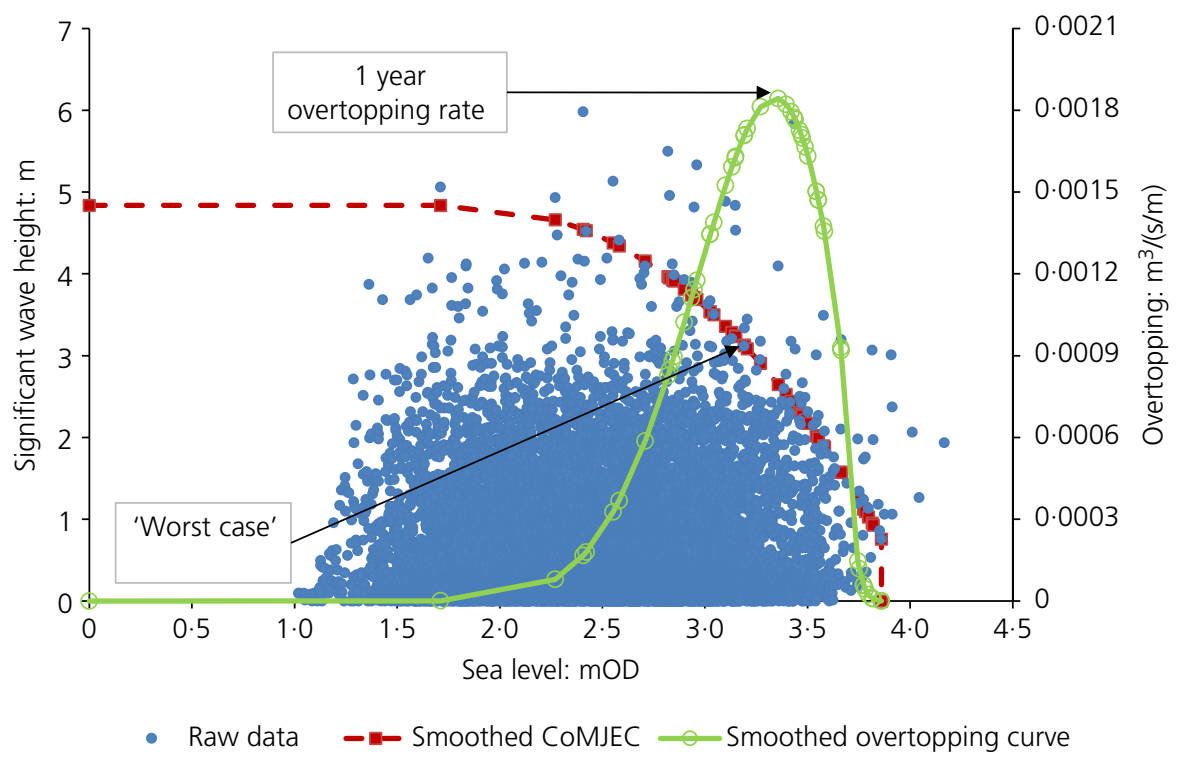

Figure 3. Determination of the peak overtopping rate from a 1 year COMJEC for a typical sea defence structure

of the Beach Management Manual (Simm et al., 1996), Defra guidance on the best practice for joint probability (Defra, 2005), as well as in the second edition of the Rock Manual (Ciria et al., 2007). The Beach Management Manual and the Rock Manual were also subsequently cited by British Standards. It was an essential approach for many at a time when both time-series sea levels and wave data were expensive to obtain, yet published information on marginal extremes was readily available, particularly sea-level extremes (e.g. Coles and Tawn, 1990; Dixon and Tawn, 1994, 1997; Graff, 1981).

The InJoPA approach takes the rather straightforward approach that offshore waves are 'more (positive, possibly high correlation)' or 'less (low or negative correlation)' likely to occur at extreme sea levels for any given site. The aim is to estimate the equivalent output from the CoMJEC when only marginal extreme data are available. It was defined as a product of the marginal probabilities of the wave height $\left(H_{\mathrm{s}}\right)$ and the sea level $(\eta)$ multiplied by a correlation factor $\left(C_{\mathrm{F}}\right)$ of the form below, where wave heights and sea levels are for coincident high sea-level conditions

3. $p\left(H_{\mathrm{s}} \geq y \cap \eta \geq x\right) \approx C_{\mathrm{F}} p\left(H_{\mathrm{s}} \geq y\right) p(\eta \geq x)$

The value of the RV corresponding to the response probability of interest is then determined in the same way as for the CoMJEC.
For the InJoPA approach, there are potentially several different ways in which the joint probability relationship can be determined. The two main approaches are as follows.

- Simplified approach: Ciria et al. (2007), Hawkes and Hague (1994) and Simm et al. (1996): here the correlation factor is determined spatially based on all wave directions combined. This replicates the way this approach was originally described in Hawkes and Hague (1994), although it had been in common use in consultancy studies since 1990.

- Desk study approach: Defra (2005): here the correlation factor is determined spatially based on the level of dependency between wave heights and sea levels for the wave direction sector (e.g. broadly easterly or broadly westerly) in which dependence is highest.

For the simplified approach, the correlation factor is defined from the level of dependency originally in terms of four discrete levels. This was later increased to five in Defra (2005) to accommodate for the much higher dependence found between wave height and surge, as detailed in Figure 4. For the desk study approach, the correlation factor is determined from the level of correlation, rather than the more broad definition of dependency. This gives a greater range of correlation factors more appropriate for the location of interest.

A comparison based on the InJoPA simplified approach against the CoMJEC approach determined by JS for a location on the west coast of the UK is given in Figure 5. This figure shows 


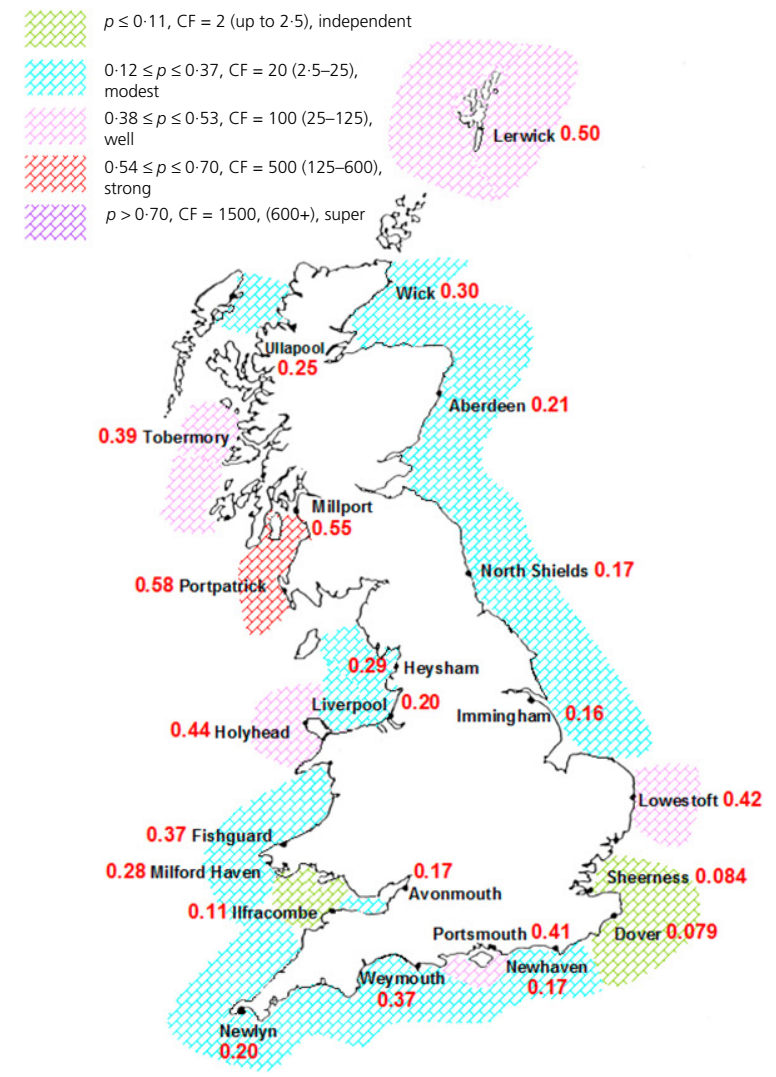

(a)

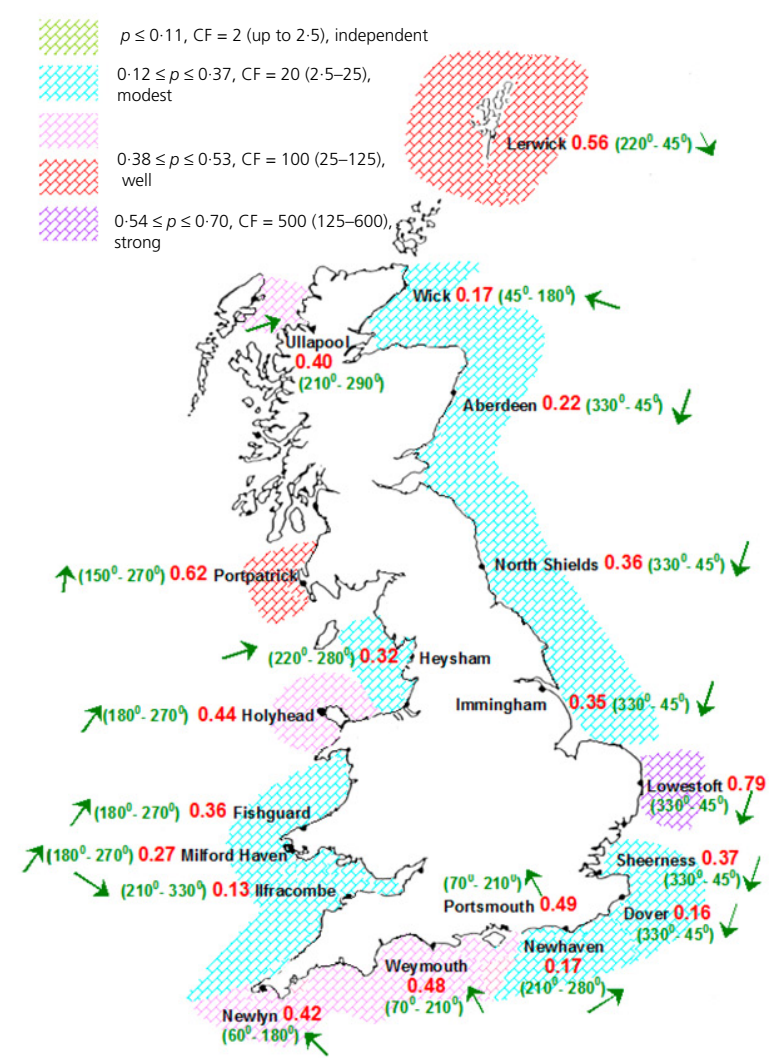

(b)

Figure 4. Levels of dependency and correlation for the different InJoPA approaches outlined in Defra (2005). (a) Simplified approach, where correlation is based on the level of dependency (Figure 4.1, Defra 2005). The numbers in both figures indicate the correlation coefficient for a threshold of 0.90; (b) Desk-study approach, where correlation is determined spatially based on wind direction (Figure 4.2, Defra 2005). The arrows indicate the direction for which the correlation is highest

the five cases of dependency outlined in Figure 4 against the CoMJEC approach determined from the data. This gives an indication of the approximate nature of this approach, where the curve corresponding to good dependency is probably the best match to the CoMJEC. Good dependency suggests a reasonable match to wave heights when considering sea levels of less than about $5.9 \mathrm{mOD}$, yet typically significantly overestimates wave heights as increasingly extreme sea levels are considered. Different locations would give differing levels of comparison to the COMJEC, and the importance of the match would very much depend on the RV being considered and the location of any predictions. If, for example, rock sizes on a deep water harbour arm were to be considered, design wave heights from the CoMJEC or the InJoPA approach would be similar as rock sizes in deep water tend to be dominated by extreme wave heights. However, differences may well be significant if considering the overtopping rate of a shoreline structure fronted by a high beach, where the overtopping rate is affected significantly by breaking wave heights approaching extreme sea levels.
Although originally developed for cases where only information on marginal extremes was available, and described in Defra (2005) as such, this approach has in many cases been utilised as a simplified approach for a joint probability study, and continues to be used in this way with many defences designed using this method as a basis. Understandably, this has led to estimates of RVs that should be treated with some caution. This was demonstrated, for example, in an analysis of the RP of storms in December 2013 within the Liverpool Bay region. UKCMF (2014) estimated the RP of this event at 9300 years using the InJoPA approach. An analysis for the same region by Wadey et al. (2015) but this time using the CoMJEC approach indicated a much lower $\mathrm{RP}$ of this same event (given as $>200$ years). The differences between these approaches could also be more significant if considering a joint probability curve for nearshore conditions against either of the InJoPA approaches, where the correlation factors have been determined based on offshore conditions. 


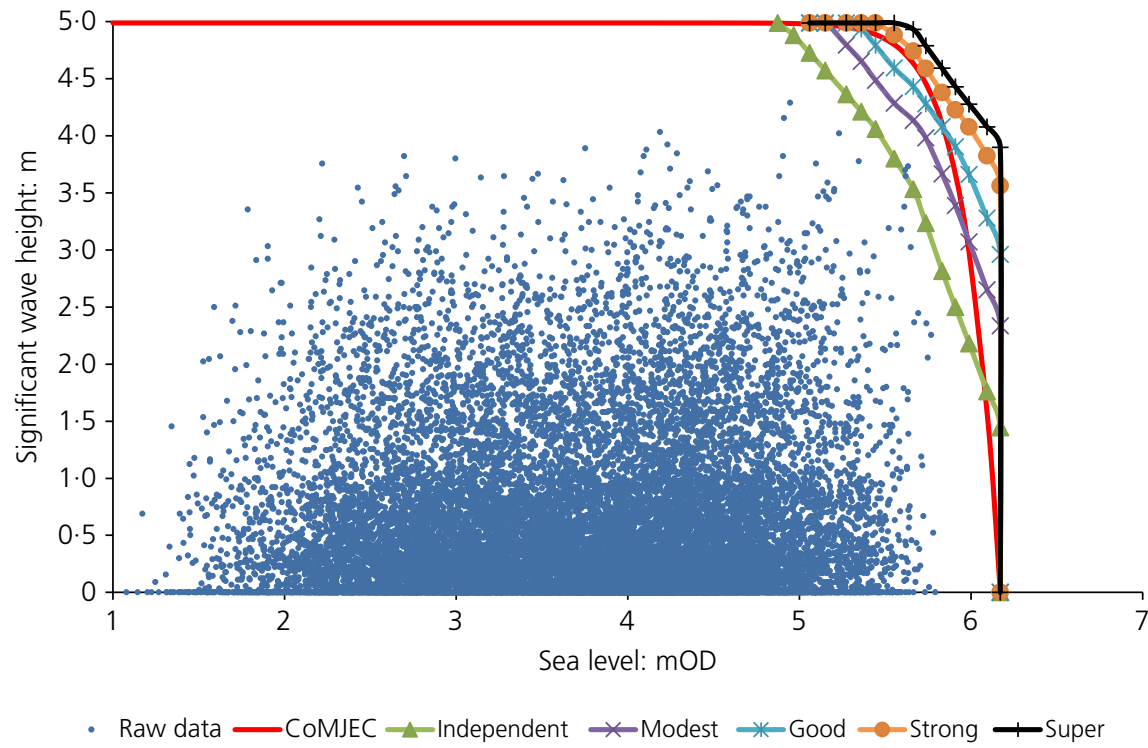

Figure 5. Comparison of the InJoPA simplified approach against the CoMJEC for a 100 year RP condition for an unspecified UK location

\subsection{RV approach}

With the development of the JS approach in the late 1990s, combined with the increased availability of time-series wave and sea-level data from about the early 1990s, the RV approach became established as a practical option in joint probability studies. This enabled the RV of interest corresponding to the required RP or exceedance probability to be estimated directly from the distribution of the (univariate) response itself, as opposed to combinations of different environmental parameters. Based on stochastically simulated data sets, much larger than the largest RP of interest, the RV was determined for each simulated wave and sea-level combination, or occasionally surge instead of sea level where it could be reliably estimated. An empirical ranking procedure (see e.g. Hawkes et al., 2002) was then used to determine the RV corresponding to the exceedance probability required.

This development for the first time enabled RVs to be determined robustly notwithstanding the limitations of the response functions themselves and the statistical methodology utilised. It also removed the inconsistency in the joint probability curve techniques, in that these techniques excluded conditions outside the range inherently defined by Equation 2 where, for example, long period waves or small waves occurring at very extreme sea levels could result in significant values of the RV. This is demonstrated in Figure 6 for the overtopping response utilising the same data set considered for the CoMJEC approach in Figure 3, Section 3.1. On applying the RV approach, and utilising the same countback technique as applied in Section 3.1, a 1 year peak overtopping rate equal to $0.0064 \mathrm{~m}^{3} /(\mathrm{s} / \mathrm{m})$ is obtained. This figure is approximately 3.5 times greater than the corresponding estimate from the CoMJEC approach outlined in Figure 3. Figure 6 also shows the curve that for different combinations of wave and sea-level conditions, and on the assumption of a constant wave steepness, could be anticipated to give a 1 year overtopping rate equal to $0 \cdot 0064 \mathrm{~m}^{3} /(\mathrm{s} / \mathrm{m})$.

\section{Conclusions}

The evolution of joint probability methods in the analyses and assessment of sea defence structures has naturally evolved based on the availability of data, as well as the advancement in computer power and available methods. Prior to the 1990s, a lack of coincident wave height and sea-level data meant that the levels of correlation between these different data sets could not be investigated to any great detail. Although data on marginal extremes were freely available, these were usually based on annual maxima sea-level records at certain ports around the UK, or historic wave databases such as those published by Hogben and Lumb (1967). These and similar data sets were therefore often utilised to estimate 'design parameters', using the engineering judgement approach to assess the performance of sea defence structures. With the expansion of the UK Tide Gauge Network in the late 1980s and early 1990s, more robust joint probability curve techniques started to emerge, although these were hampered to an extent by the cost of data at this time. Based on the concept of design wave heights and sea levels, these quickly became established among the coastal engineering community. This was probably helped by the similarity to the well-known 'engineering judgement' approaches that almost by default had existed up to this time, as well as 


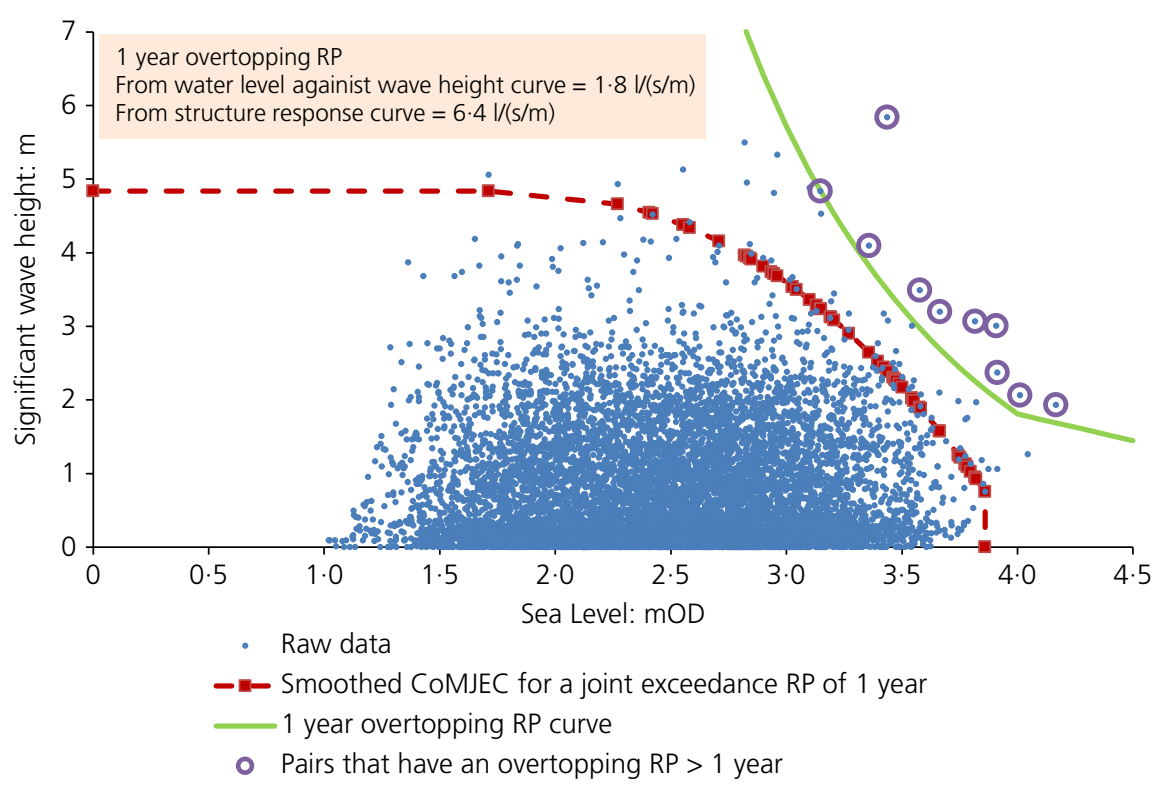

Figure 6. Comparison of the COMJEC and the RV approaches in the determination of a 1 year peak overtopping rate

the experience of many coastal engineers, who had come from a civil engineering background and hence were familiar with the concept of design parameters.

With the advent of the JS approach in the mid-1990s, it was anticipated that the different joint exceedance curve techniques would gradually fade from use in preference to the more robust RV (or risk-based approaches). This does not appear to be the case and they have continued to be used extensively across consultancy studies. The 'easy' presentation of results, the consequent ease of use and the familiar concept of apparent design conditions probably explain why they have continued to be used extensively. In addition, the fact that the production of joint exceedance curves was a major part of the output from JS may have led users to the conclusion that this was a methodology for a more robust CoMJEC approach, rather than to introduce them to the RV approach. However, the inconsistency in the estimation of RVs for different RPs rarely seems to be appreciated or accounted for, and as a result, RVs may be significantly biased, with potentially significant impacts on the analysis of wave forces or overtopping levels. The same problem should not exist with the InJoPA approach, which was developed for cases where only information on marginal extremes was available. Techniques utilising the JS approach were therefore not an option in these cases. The InJoPA approach has, however, been used extensively in studies where information on the joint occurrence of wave and sea-level data are readily available. The approximate nature of this approach therefore includes significant uncertainties, particularly as there is a degree of flexibility in how it can be applied, with a consequent variation in the results obtained.

\section{Acknowledgements}

The authors thank Tim Hunt and David Hornby at the Environment Agency for their helpful comments and patience in the writing of this paper.

\section{REFERENCES}

Ciria, CUR and CETMEF (2007) The Rock Manual. The Use of Rock in Hydraulic Engineering, 2nd edn. C683, Ciria, London, UK.

Coles SG and Tawn JA (1990) Statistics of coastal flood prevention. Philosophical Transactions of the Royal Society of London A: Mathematical, Physical and Engineering Sciences 332(1627): 457-476.

Defra (Department for Environment, Food and Rural Affairs) (2005) Joint Probability: Dependence Mapping and Best Practice: Technical Report on Dependence Mapping. London, UK, R\&D Technical Report FD2308/TR1.

De Michele C, Salvadori G, Passoni G and Vezzoli R (2007) A multivariate model of sea storms using copulas. Coastal Engineering 54(10): 734-751.

Dixon MJ and Tawn JA (1994) Extreme Sea-levels at the UK A-Class Sites: Site-by-Site Analyses. Proudman Oceanographic Laboratory, Bidston, UK, Internal Document No. 65.

Dixon MJ and Tawn JA (1997) Spatial Analysis for the UK Coast. Proudman Oceanographic Laboratory, Bidston, UK, Internal Document No. 112.

Ewans K and Jonathan P (2014) Evaluating environmental joint extremes for the offshore industry using the conditional extremes model. Journal of Marine Systems 130: 124-130. 
Gouldby B, Wyncoll D, Panzeri M et al. (2017) Multivariate extreme value modelling of sea conditions around the coast of England. Proceedings of the Institution of Civil Engineers - Maritime Engineering 170(1): 3-20, https://doi.org/10.1680/jmaen.2016.16.

Graff J (1981) An investigation of the frequency distributions of annual sea level maxima at ports around Great Britain. Estuarine, Coastal and Shelf Science 12(4): 389-449.

Hames D (2006) Investigation of the Joint Probability of Waves and High Sea Levels along the Cumbrian Coastline. PhD Thesis, University of Plymouth, Plymouth, UK.

Hames D, Gouldby B, Hawkes P et al. (2013) Prototype Wave Overtopping Tool for MDSF2. Report for the Environment Agency. Wallingford, UK, Project No. FCPIF00366B00.

Hawkes PJ and Hague RC (1994) Validation of Joint Probability Methods for Large Waves and High Water Levels. Wallingford, UK, HR Wallingford Report SR 347.

Hawkes PJ, Gouldby BP, Tawn JA and Owen MW (2002) The joint probability of waves and water levels in coastal engineering design Journal of Hydraulic Research 40(3): 241-251.

Heffernan JE and Tawn JA (2004) A conditional approach for multivariate extreme values (with discussion). Journal of the Royal Statistical Society, Series B (Statistical Methodology) 66(3): 497-546.

Hogben N and Lumb FE (1967) Ocean Wave Statistics - A Statistical Survey of Wave Characteristics Estimated Visually from Voluntary Observing Ships Sailing Along the Shipping Routes of the World. HMSO, London, UK.

HRL (Hydraulics Research Limited) (1990) Joint Probability of Waves and Water Levels on the North Wales Coast. Hydraulics Research Limited, Wallingford, UK, Report Number EX 2133.

HR Wallingford (1992) UK South Coast Shingle Study - Joint Probability Assessment. HR Wallingford, Wallingford, UK, Report SR 315.

HR Wallingford (2000a) The Joint Probability of Waves and Water Levels: JOINSEA - A Rigorous but Practical New Approach, HR Wallingford \& Lancaster University, Wallingford, UK. HR Wallingford, Report SR537.

HR Wallingford (2000b) The Joint Probability of Waves and Water Levels: JOINSEA - Version 1.0, User Manual,
HR Wallingford \& Lancaster University, Wallingford, UK, Report TR71.

HR Wallingford (2004) National Flood Risk Assessment 2004: Supported by the RASP HLM Methodology, Report for the Environment Agency. HR Wallingford, Wallingford, UK. Report SR659.

HR Wallingford (2015) State of the Nation: Coastal Boundary Conditions Report for the Environment Agency. HR Wallingford, Wallingford, UK, Report Number 30, Reference MCR538930-R00-01.

Kotz S and Nadarajah S (1999) Extreme Value Distributions, Theory and Applications. Imperial College Press, London, UK.

Ledford AW and Tawn JA (1996) Statistics for near independence in multivariate extreme values. Biometrika 83(1): 169-187.

Ledford AW and Tawn JA (1997) Modelling dependence within joint tail regions. Journal of the Royal Statistical Society, Series B 59(2): 475-499.

Met Office (2014) Winter Storms, December 2013 to January 2014. Met Office, London, UK. See https://www.metoffice.gov. uk/climate/uk/interesting/2013-decwind (accessed 12/02/2018).

Sayers PB, Hall JW and Meadowcroft IC (2002) Towards risk-based flood hazard management in the UK. Proceedings of the Institution of Civil Engineers - Civil Engineering 150(1): 36-42, https://doi.org/10.1680/cien.2002.150.5.36.

Serinaldi F (2014) Dismissing return periods. Stochastic Environmental Research and Risk Assessment 29(4): 1179-1189.

Simm J, Brampton AH, Beech NW and Brooke JS (1996) Beach Management Manual. Construction Industry Research and Information Association, London, UK, vol. 153.

UKCMF (UK Coastal Monitoring and Forecasting Service) (2014) Factual Report into the Coastal Storms of December 2013 and January 2014 Including Joint Sea Level and Wave Analysis, Final Report to Environment Agency/National Resources Wales. JBA Consulting, Skipton, UK.

Wadey MP, Brown JM, Haigh ID, Dolphin T and Wisse p (2015) Assessment and comparison of extreme sea levels and waves during the 2013/14 storm season in two UK coastal regions. Natural Hazards and Earth System Sciences 15(10): 2209-2225.

\section{How can you contribute?}

To discuss this paper, please email up to 500 words to the editor at journals@ice.org.uk. Your contribution will be forwarded to the author(s) for a reply and, if considered appropriate by the editorial board, it will be published as discussion in a future issue of the journal.

Proceedings journals rely entirely on contributions from the civil engineering profession (and allied disciplines). Information about how to submit your paper online is available at www.icevirtuallibrary.com/page/authors, where you will also find detailed author guidelines. 